\title{
Surgical resections in parous patients with distal ileal and colonic Crohn's disease
}

\author{
C U Nwokolo, W C Tan, H A Andrews, R N Allan
}

\begin{abstract}
The surgical resection rates among parous women with distal ileal and colonic Crohn's disease have been compared with resection rates among distal ileal $(n=197)$ and colonic $(n=332)$ Crohn's disease patients. Thirty of 44 parous women with distal ileal Crohn's disease and 28 of 44 with colonic Crohn's disease had achieved their first pregnancy on average 8 years and 6.2 years respectively before the diagnosis of Crohn's disease was established. Resections for each patient were negatively correlated with parity in both groups. (Distal ileal disease $(p=0.034, r s=0.3207)$, colonic disease $(p=0.051, r s=-0.2960))$. Patients with distal ileal Crohn's disease and a history of pregnancy at diagnosis $(n=30$, mean follow $u p=15$ years) had fewer resections/patient when compared with the published resection group: mean (SD); 1.17 (0.65) v 1.57 (1.05), $\mathrm{p}=0.006$. Patients with colonic Crohn's disease and a history of pregnancy at diagnosis $(n=28$, mean follow up $=16.5$ years) had fewer resections/patient when compared with the published resection group: mean (SD); 0.68 $(0.77) v 1.05(0.77), p=0.019$. In summary, patients with distal ileal and colonic Crohn's disease, who had been pregnant in the past subsequently need fewer surgical resections. Pregnancy could influence the natural history of Crohn's disease either by decreasing immune responsiveness or by retarding fibrous stricture formation, which is the commonest indication for surgical intervention.
\end{abstract}

(Gut 1994; 35: 220-223)

The peak incidence of Crohn's disease occurs between the ages of 15 to 40 years ${ }^{1}$ and coincides with the childbearing years. The interaction between Crohn's disease and pregnancy has been the subject of several studies. In 1956 it was suggested that Crohn's disease relapsed during pregnancy. ${ }^{2}$. This view was challenged in 1972 by Norton et al who suggested that Crohn's disease activity was unaffected by pregnancy. ${ }^{3}$ Khosla suggested that the activity of Crohn's disease during pregnancy reflects the disease activity at the time of conception. ${ }^{4}$ Measurement of Crohn's disease activity, however, as a single point assessment in a lifelong disease is an incomplete measure of longterm outcome.

The frequency of surgical intervention for either stricture formation or persistent symptoms unresponsive to medical treatment in Crohn's disease is a good measure of longterm outcome. In the small bowel, chronic inflammation usually leads to fibrous stricture formation and recurrent obstructive symptoms, while in the large bowel, surgery is usually required for chronic persistent inflammation unresponsive to anti-inflammatory or immunosuppressive treatment.

Pregnancy has a significant effect on the maternal immune system. Failure of maternal rejection of the fetus, which is effectively a foreign allograft, is evidence that the maternal immune system may be modified. Although a specific defect in the maternal immune system has not yet been defined, there are several factors in maternal blood that decrease maternal immune responsiveness. ${ }^{5}$ In particular a soluble protein produced by fetal lymphocytes decreases the response of maternal lymphocytes to phytohaemagglutinin and mixed lymphocytic culture. ${ }^{67}$

Increased laxity of fibrous tissues has been seen during pregnancy in many mammalian species affecting the sacroiliac joints, public symphysis, and cervix. ${ }^{8}$ The effects are mediated by relaxin, an insulin like peptide produced by the corpus luteum of pregnancy. ${ }^{9}$

These pregnancy induced effects on the immune system and fibrous tissue could affect the bowel in Crohn's disease: reduce the chronic inflammatory response, fibrous tissue formation, and thus reduce the frequency of surgical intervention.

Based on these findings this study examined whether there is an association between parity and surgical resection in Crohn's disease patients. We also compared surgical resection rates among patients who had been pregnant before the diagnosis of Crohn's disease was established with published resection data for all our patients with distal ileal and colonic Crohn's disease.

\section{Methods and patients}

The demographic data for Crohn's disease patients attending the General Hospital, Birmingham inflammatory bowel disease clinics are held on a computerised database. Using an in house software package, the names and hospital numbers of patients who had achieved pregnancy in the 34 years between 1958 and 1992 were obtained. Additional data including the duration of patient follow up, details of pregnancies, surgical intervention, and smoking habits were obtained from their hospital records.

Crohn's disease classification - Patients were classified into four groups according to the initial site of disease and the site of the first recurrence: (1) Distal ileal disease - initial disease affecting the terminal ileum (with or without caecal involvement) with first recurrence (where relevant) in the neoterminal ileum or at the anastomosis; (2) colonic disease - initial disease in the colon or proximal rectum with first recurrence in residual colon or at the anastomosis; 


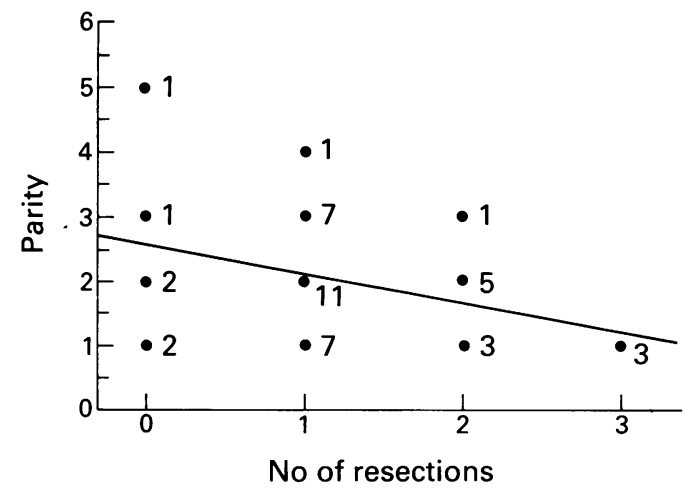

Figure 1: Correlation of parity and number of resections among 44 parous patients with distal ileal Crohn's disease. $(p=0 \cdot 034, r s=-0 \cdot 3207 ;$ Spearman rank correlation coefficent). The numbers beside the data points are the number of patients represented by each point.

(3) ileocolonic disease - initial disease in the ileum and colon (distal to the caecum and ascending colon); (4) diffuse small bowel disease - initial extensive disease in the jejunum with or without ileal involvement. Patients with perianal disease alone with excluded from the study.

Surgical resections - Resection, by pass or strictureplasty for focal macroscopic disease was included as a single resection.

Pregnancy - All pregnancies that reached a gestational age of 28 weeks were included and the year of each pregnancy was recorded.

Diagnosis of Crohn's disease - The diagnosis and extent of disease was confirmed in all patients by histology, endoscopy or high quality radiology and the date of diagnosis was based on this evidence.

Smoking - Patients were classified as either smokers or non-smokers and the number of cigarettes per day was recorded.

Published resection data - This has been reported for 227 patients with distal ileal Crohn's disease $^{10}$ and recently updated ${ }^{11}$ and 350 patients with colonic Crohn's disease. ${ }^{12}$

Statistical analysis - Parity and the number of resections per patient were correlated in each disease group using the Spearman rank correlation coefficient. Parametric statistics (unpaired $t$ test) were used to compare resection rates among patients who had been pregnant before

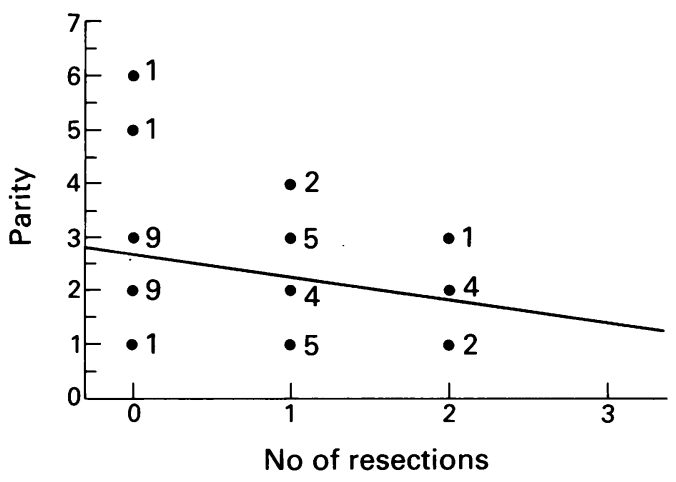

Figure 2: Correlation of parity and number of resections among 44 parous patients with colonic Crohn's disease. $(p=0.051, r s=-0.2960 ;$ Spearman rank correlation coffecient). The numbers beside the data points are the number of patients represented by each point.
TABLE I Distal ileal Crohn's disease

\begin{tabular}{|c|c|c|}
\hline Mean & $\begin{array}{l}\text { Published data } \\
(n=197)\end{array}$ & $\begin{array}{l}\text { History } \\
\text { of pregnancy } \\
(n=30)\end{array}$ \\
\hline $\begin{array}{l}\text { Age at diagnosis (SD) } \\
\text { Duration of follow up (y) } \\
\text { Resections/patient (SD) } \\
\text { Interval from first to second }\end{array}$ & $\begin{array}{l}33(14 \cdot 6) \\
17 \\
1.57(1.05)\end{array}$ & $\begin{array}{l}32(5 \cdot 97) \\
15 \\
1 \cdot 17(0.65)\end{array}$ \\
\hline resection $(y)$ & 10 & 13 \\
\hline $\begin{array}{l}\text { Proportion with } 0 \text { or } 1 \\
\text { resection (\%) }\end{array}$ & 56 & 77 \\
\hline
\end{tabular}

the diagnosis of Crohn's disease with the published resection data (from which the data for the pregnancy group had been excluded). Statistical analysis was performed using Oxstat (Microsoft Corporation).

\section{Results}

One hundred and forty five patients had been pregnant between 1958-1992 of whom 111 had complete hospital records. Thirty four patients had either incomplete obstetric histories, were lost to follow up early in the course of their disease, had their disease reclassified or incomplete hospital records. Of the 111 with complete hospital records 88 patients had either distal ileal disease $(n=44)$ or colonic disease $(n=44)$. Twenty three patients had either diffuse small bowel $(n=7)$ or ileocolonic disease $(n=16)$.

DISTAL ILEAL AND COLONIC CROHN'S DISEASE

Thirty of 44 patients with distal ileal disease had been pregnant before the diagnosis of Crohn's disease (mean interval between first pregnancy and diagnosis of Crohn's disease $=8$ years).

Twenty eight of the 44 patients with colonic disease had been pregnant before the diagnosis of Crohn's disease (mean interval between first pregnancy and diagnosis of Crohn's disease $=6 \cdot 2$ years). Sixty per cent of all parous patients smoked 3-20 cigarettes daily.

\section{Correlation analysis}

Among the 44 patients with distal ileal Crohn's disease there was a negative correlation between parity and the number of resections $(p=0.034$, $\mathrm{rs}=-0.3207$; Spearman rank correlation coefficient) (Fig 1). The resections recorded were either ileal, ileocaecal or right hemicolectomy except for one strictureplasty and one ileocolonic by pass.

TABLE II Colonic Crohn's disease

\begin{tabular}{lll}
\hline Mean & $\begin{array}{l}\text { Published data } \\
(n=332)\end{array}$ & $\begin{array}{l}\text { History } \\
\text { of pregnancy } \\
(n=28)\end{array}$ \\
\hline $\begin{array}{ll}\text { Age at diagnosis (SD) } \\
\begin{array}{l}\text { Duration of follow up (y) } \\
\text { Resections/patient (SD) }\end{array}\end{array}$ & $\begin{array}{l}39(16 \cdot 2) \\
\begin{array}{l}\text { Interval from first to second } \\
\text { resection (y) }\end{array}\end{array}$ & $\begin{array}{l}31(7 \cdot 22) \\
16 \cdot 5\end{array}$ \\
$\begin{array}{l}\text { Proportion with 0 or 1 } \\
\text { resection (\%) }\end{array}$ & 14 & $0 \cdot 68(0 \cdot 77)^{\star}$ \\
\hline
\end{tabular}

$\star-\mathrm{p}=0.019$ unpaired $t$ test. 
Similarly among the 44 patients with colonic Crohn's disease there was a negative correlation between parity and the number of resections $(\mathrm{p}=0.051$, $\mathrm{rs}=-0.2960$; Spearman rank correlation coefficient)(Fig 2). Seven patients required a second resection. Six patients had a proctectomy for active rectal disease and one panproctocolectomy was performed in a patient who initially had a left hemicolectomy.

\section{Comparative resection data}

There was no significant difference in the duration of follow up between the parous and the published resection group.

Table I shows the published resection data $(n=197)$ compared with resection data of the 30 patients that had been pregnant before the diagnosis of distal ileal Crohn's disease (history of pregnancy group).

Table II shows the published resection data $(n=332)$ compared with resection data of the 28 patients that had been pregnant before the diagnosis of colonic Crohn's disease (history of pregnancy group)

\section{Subset analysis}

Distal ileal disease: there was no difference in the resection rates of patients pregnant before $(1 \cdot 17$ SD 0.65$)$ and after $(1 \cdot 14$ SD $0 \cdot 86)$ the diagnosis of Crohn's disease $(p=0.928)$. The resection rates of patients pregnant after the diagnosis of Crohn's disease was $1 \cdot 14$ SD $0 \cdot 86$ compared with 1.57 SD 1.05 for the published resection group $(\mathrm{p}=0.099)$.

Colonic disease: there was no difference in the resection rates of patients pregnant before $(0.68$ SD 0.77$)$ and after $(0.69$ SD 0.70$)$ the diagnosis of Crohn's disease $(p=0.969)$. The resection rates of patients pregnant after the diagnosis of Crohn's disease was 0.69 SD 0.70 compared with 1.05 SD 0.77 for the published resection group $(\mathrm{p}=0.079)$.

\section{DIFFUSE SMALL BOWEL DISEASE}

Four of seven patients had been pregnant before the diagnosis of Crohn's disease. In these four patients, after a mean follow up of 17 years, the mean resection rate was $3 \cdot 3$.

\section{ILEOCOLONIC DISEASE}

Ten of 16 patients had been pregnant before the diagnosis of Crohn's disease. In these 10 patients, after a mean follow up of $17 \cdot 6$ years, the mean resection rate was $2 \cdot 3$.

\section{Disussion}

The correlation analysis suggests that parity (before and after the diagnosis of Crohn's disease) and surgical resections are associated in patients with distal ileal and colonic Crohn's disease. Increasing parity reduces the need for further surgical resections. The subgroup analysis suggests that this trend is present even in patients who became pregnant after the diagnosis of Crohn's disease was made. These results might be explained by severely ill patients with Crohn's disease having impaired fertility or no desire for children at that time. The comparative resection data suggest, however, that even patients who had been pregnant by the time of diagnosis of their Crohn's disease need fewer surgical resections subsequently. The number of resections/patient is lower in the parous patients and a history of pregnancy at the time of diagnosis of Crohn's disease is associated with a longer interval between the first and second resection. A larger proportion of patients in the parous groups have had either no or only one resection compared with patients in the published resection group.

The differences could reflect changing surgical practice between 1944-1992. The principles of management, however, of patients with Crohn's disease have been consistent over this time. While surgical technique has improved the indications and the threshold for recommending surgery have not really changed. This was confirmed by a recent analysis of the patients with distal ileal disease, which showed that the resection rates have not changed with time."

There was no significant sex differences in the published resection data so that differences in resection rates in men cannot bias the data in the combined group.

In addition smoking habits among the parous patients was similar to that among the patients in the published resection group.

It is possible that patients that have experienced childbirth, are more tolerant of pain and discomfort and thus tend to delay surgery.

Multiple perioperative blood transfusions may decrease recurrence in Crohn's disease by decreasing immune responsiveness. ${ }^{13}$ Similarly maternal immune responsiveness is decreased during pregnancy. ${ }^{14}$ In vitro studies suggest that although maternal lymphocytes do not exhibit a specific immune defect, ${ }^{515}$ fetal lymphocytes secrete a soluble protein that is potentially immune modulatory. ${ }^{67}$ In some species the uterus 'remembers' previous pregnancies and this may be mediated be memory lymphocytes persisting within the uterine wall. ${ }^{16}$ Multiparity may therefore lead to subtle acquired immune deficits.

When fibrous tissue is exposed to relaxin, an insulin like peptide produced by the corpus luteum of pregnancy, collagen fibres are dissolved and disorganised. ${ }^{17}{ }^{18}$ The effects of relaxin have been widely reported in tissues not participating in reproduction. ${ }^{19-25}$ Whether the fibrosis in the bowel wall that leads to surgical resection in Crohn's disease might be affected is unknown.

This study suggests that patients with a history of pregnancy at the time of diagnosis of their Crohn's disease have fewer surgical resections subsequently. The reasons are not yet entirely clear but may be related to the effect of pregnancy on the immune system and fibrous tissue. A history of pregnancy at the time of diagnosis is a favourable prognostic indicator in both distal ileal and colonic Crohn's disease. Further studies are needed to investigate the effect of parity on non-surgical indices of Crohn's disease activity - for example, relapse 
rates, steroid requirement, and inflammatory markers.

We are grateful to Margaret Bicknell and Jacqui Baker for assistance with the patients' hospital records. This study was an oral presentation at the 1992 Autumn Meeting of the British Society of Gastroenterology.

1 Rhodes J, Harries AD, Mayberry JF, Dew MJ. Clinical features of Crohn's disease. In: Misiewicz JJ, Pounder RE, Venables CW, eds. Diseases of the gut and pancreas. Ist ed. Oxford: Blackwell Scientific, 1990: 766-95.

2 Crohn BB, Yarnis H, Korelitz BI. Regional ileitis complicating. pregnancy. Gastroenterology 1956; 31: 615-2.

3 Norton RA, Patterson JF. Pregnancy and regional ileitis. Obstet Gynecol 1972; 40: 711-2.

4 Khosla R, Willoughby CP, Jewell DP. Crohn's disease and pregnancy Gut 1984; 25:52-6.

5 Gill TJ 111 . Immunity and pregnancy. CRC Crit Rev Immunol 1985; 5: 201-27.

6 Bassett M, Coons TA, Wallis W, Goldberg EH, Williams RC. Suppression of stimulation in mixed lymphocytic culture by newborn splenic lymphocytes in the mouse. F Immunol newborn splenic lym $1977 ; 119: 1855-7$.

7 Granberg C, Manninen K, Toivanen P. Cell-mediated lympholysis by human neonatal lymphocytes. Clin Immunol Immunopathol 1976; 6: 256-63.

8 Hisaw FL. Experimental relaxation of the public ligament of the guinea pig. Proc Soc Exp Biol Med 1926; 23: 661-3.

9 Fevoid HL, Hisaw FL, Meyer RK. The relaxative hormone of corpus luteum. Its purification and concentration. $\mathcal{f} \mathrm{Am}$ Chem Soc 1930; 52: 3340-8.

10 Higgens CS, Allan RN. Crohn's disease of the terminal ileum. Gut 1980; 21: 933-40.

11 Andrews HA, Keighley MRB, Alexander-Williams J, Allan RN. Strategy for management of distal ileal Crohn's disease. RN. Strategy for manageme
$B r \mathscr{F}$ Surg 1991; 78: 679-82.
12 Andrews HA, Lewis $P$, Allan RN. Prognosis after surgery for colonic Crohn's disease. Br $\mathcal{F}$ Surg 1989; 76: $118+90$

13 Peters RW, Fry RD, Fleshman JW, Kodner IJ. Multiple blood transfusions reduce the recurrence rate of Crohn' disease. Dis Colon Rectum 1992; 32: 749-53.

14 Anderson JM. Nature's transplant: the transplantation immunology of viviparity. New York: Appleton-CenturyCrofts, 1972 .

15 Gill TJ, 111, Repetti CF. Immunological and genetic factors influencing reproduction. Am f Pathol 1979; 95: 463-570.

16 Beer AE, Billingham RE. Host responses to intrauterine tissue, cellular and fetal allografts. 7 Reprod Fetril 1974; 21 : tissue,

17 Chihal HJ, Espey LL. Utilization of the relaxed symphysis publis of guinea pigs for clues to the mechanism of ovulation. Endocrinology 1973; 93: 1441-5.

18 Frieden EH, Hisaw FL. The mechanism of symphyseal relaxation. The distribution of reducing groups, hexoseamine, and proteins in symphyses of normal and relaxed guinea pigs. Endocrinology 1951; 48: 88-97.

19 Olfesky JM, Saekow M, Kroc RL. Potentiation of insulin binding and insulin action by purified porcine relaxin. $A n n$ $N Y$ Acad Sci 1982; 380: 200-15.

20 Plunkett ER, Squires BP, Heagy FC. Effect of plaxin on thyroid function in the rat. $\mathcal{F}$ Endocrinol $1963 ; 26$ : 331-8.

21 Schwabe $C$. Relaxin in connective tissue diseases. In: Bigazzi M, Greenwood FC, Gasparri F, eds. Biology of relaxin and its role in the human. Amsterdam: Excerpta Medica, 1983: role in

22 Kakouris H, Eddie LW, Summers RJ. Cardiac effects of relaxin in the rat. Lancet 1992; 339: 1076-9.

23 Steinetz BG, Whitaker PG, Edwards JRG. Maternal relaxin concentrations in diabetic pregnancy. Lancet 1992; 340: $752-5$.

24 Casten GG, Boucek RJ. Use of relaxin in the treatment of schleroderma. FAMA 1958; 166: 319-24.

25 Casten GG, Gilmore HR, Houghton FE, Samuels SS. A new approach to the management of obliterative peripheral arterial disease. Angiology 1960; 11: 408-14. 